\title{
Research Paper: Effect of Hospital Incident Command System Establishment on the Preparedness Level of Disaster Committee and Nursing Staff of Imam Ali Hospital, Zarand, Iran, 2010
}

\author{
Zahra Borhannejad ${ }^{1}$, Sayed Baqer Sadat Madah ${ }^{2 *}$, Hamid Reza Khankeh ${ }^{2,3}$ (D), Masoud Falahi Khoshknab ${ }^{2}$ (D), Pourya Rezasoltani ${ }^{4}$ \\ Shoukofhe Ahmadi \\ 1. Research Center in Emergency \& Disaster Health, University of Social Welfare and Rehabilitation Sciences, Tehran, Iran. \\ 2. Department of Nursing, University of Social Welfare and Rehabilitation Sciences, Tehran, Iran. \\ 3. Department of Clinical Science and Education, Karolinska Institute, Stockholm, Sweden. \\ 4. Department of Biostatistics, University of Social Welfare and Rehabilitation Sciences, Tehran, Iran.
}

\begin{tabular}{|c|c|}
\hline $\begin{array}{l}\text { Use your device to scan } \\
\text { and read the article online }\end{array}$ & Citation Borhannejad Z, Madah SBS, Khankeh HR, Falahi Khoshknab M, Rezasoltani P, Ahmadi Sh. Effect of Hospital Incident \\
\hline 口急田 & Command System Establishment on the Preparedness Level of Disaster Committee and Nursing Staff of Imam Ali Hospital, Zarand, \\
\hline iftrift. & Iran, 2010. Health in Emergencies and Disasters Quarterly. 2019; 4(2):101-108. http://dx.doi.org/10.32598/hdq.4.2.101 \\
\hline 口. & doi ${ }^{\circ} \mathrm{http}: / / \mathrm{dx}$. doi.org/10.32598/hdq.4.2.101 \\
\hline
\end{tabular}

\section{(c) (1) (3)}

Article info:

Received: 10 Aug 2018

Accepted: 27 Nov 2018

Available Online: 01 Jan 2019

\section{Keywords:}

Disaster, Hospital incident command system, Nursing, Disaster committee

\begin{abstract}
Background: The current study aimed at examining Hospital Incident Command System (HICS) on the rate of accidents and disaster preparedness committee and nursing staff of Imam Ali Hospital in Zarand, Iran.

Materials and Methods: The current semi-experimental study was conducted on the members of Crisis Committee $(\mathrm{n}=9)$ and nursing personnel $(\mathrm{n}=38)$ selected by fully count model. Data collection tools were two valid and reliable questionnaires: hospital disaster preparedness and the nurses' disaster preparedness. Hospital disaster preparedness also included a two-day workshop on hospital incident command system and the nurses' disaster preparedness included a one-day workshop on disaster management. Members of the Crisis Committee and nurses were evaluated based on hospital disaster preparedness and nurses' disaster preparedness questionnaires before and one month after intervention. SPSS V. 16 was used to analyze data.

Results: Findings of the current study indicated a major increase in the disaster preparedness of the Crisis Committee (from 88.33 to 130.88) and nurses (from 132.63 to 2077.56) after intervention; in addition, a significant improvement was observed in the nurses group $(\mathrm{P}=0.000)$

Conclusion: It was concluded that the establishment of HICS and using disaster preparedness program can improve the preparedness of hospital disaster management committee and nursing personnel against disasters.
\end{abstract}

\section{Introduction}

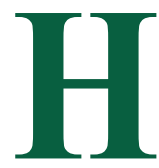

uman societies continually experience various incidents. Some of these incidents are caused by natural factors, and others are considered as human-made events such as war [1]. In case the events are so severe that there is a need for international aids, it is called "disaster" [2]. In order to stay safe during disasters, they should be either prevented or if they occur, people should be prepared and able to deal with them [3].

\section{* Corresponding Author:}

Sayed Baqer Sadat Madah, PhD.

Address: Department of Nursing, University of Social Welfare and Rehabilitation Sciences, Tehran, Iran

E-mail:drmaddah@gmail.com 
In this regard, health care centers, especially hospitals, need to have a plan to deal with disasters since they are the first reference for disaster victims. This plan should be designed in such a way to avoid confusion, chaos, and arbitrary actions, and reduce the time of the continuation of crisis and its consequences [1, 4]. In this context, the key role of nurses, as the largest group of the health team, is of great importance in management and leadership, care, coordination, support, education, and research [2]. Evidence shows that preparedness of hospitals to deal with disasters is low [5].

In Iran, studies also indicate the low preparedness of hospitals to deal with disasters [6, 7]. Higgins et al. (2004) in a study on preparedness of hospitals in Kentucky, for mass casualty events, showed that their preparedness efforts were in an early stage of development [8]. In order to improve hospitals preparedness, the application of Hospital Incident Command System (HICS) can be helpful. Its application dates back to 1970's when extensive forest fires in California caused many financial losses and casualties due to the lack of joint organization and joint planning, weak communications, inadequate resource management, and limited prediction ability.

To overcome such deficiencies, an incident command system was installed and then deployed in hospitals. This system is flexible and can make the necessary predictions at three phases of before, during, and after the incident [9]. This system includes some of the following features: having a predictable chain of command, flexible organizational charts, response checklists based on priority, ensuring the presence of functional positions, advanced documentation, common language, planning, and being cost-effective based on available resources [10].

In Iran, Hospital Disaster Management Committee (HDMC) is responsible for conducting incident management measures and executing the HICS. Thus, it is necessary to pay attention and evaluate the measures taken by this committee. In this regard, the current study aimed at assessing the effect of HICS implementation on preparedness of HDMC and nursing personnel of Imam Ali Hospital in Zarand, Iran.

\section{Materials and Methods}

The current quasi-experimental study was conducted in Imam Ali Hospital in Zarand with a history of dealing with disasters such as Bam and Zarand Earthquakes. The population covered by this hospital is 3000 people. To select samples from the HDMC of this hospital, census method was used (all members entered into the study). The members of the committee were: the hospital CEO, hospital manager, nursing director, head of finance, educational supervisor, security guard, technical officer, head of emergency department, and procurement manager.

To select samples from nurses, random sampling method was used. Inclusion criteria were: having at least a high school diploma in nursing, willing to participate in the study, not attending similar courses, and having at least one year of work experience. However, 37 of 102 nurses met the criteria.

To collect data, two questionnaires were used: the disaster preparedness questionnaire to assess preparedness of HDMC, and emergency nurse disaster preparedness questionnaire to evaluate the preparedness of nurses. The disaster preparedness questionnaire for HDMC had 161 items surveying general specifications of the hospital, disaster management structure, disaster management plan, partner organizations, security plan, procurement, discharge and transfer, fire extinguishing, structural safety, structural information, training, disinfection, coordination, communication with the media, staff, follow-up, cost reporting, documentation, expense reports, back to normal state, and post-disaster activities of participants.

Its total score is 145 ; scores $0-36$ indicate poor level; 37-72, moderate; 73-108, high; and 109-145, very high level of disaster preparedness. The disaster preparedness questionnaire for nurses consists of four sections and 73 items. First section surveys demographic characteristics, work experience, history of attending disaster management classes, and disaster response experience of participants.

Second section assesses knowledge of disaster management and nursing tasks in disaster management. The third section has 20 items related to the attitude towards disaster management. The final section consists of 25 items about nurses' practices to prepare for disaster. The instruments are scored based on a Likert scale and the total score ranges 0-280; scores 0-70 indicate poor; 71 140, moderate; 141-210, high; and 211-280, very high level of preparedness.

To obtain content validity, questionnaires were sent to 10 professors of the University of Social Welfare and Rehabilitation Sciences. After making modifications, their validity was verified. To determine reliability, the questionnaires were completed by 20 nursing personnel of Sina Hospital in Zarand twice with a two-week interval. Then, test-retest reliability was calculated using 
Kappa coefficient that was $<4.0$. Then, Pearson correlation and Cronbach's alpha coefficients were calculated for the whole questionnaire, which resulted in $\mathrm{r}=0.866$ and $\alpha=0.877$.

The HICS intervention for HDMC members included a two-day workshop on disaster preparedness. The preparation for the HICS was presented on the first day. Then, a round-table maneuver was conducted on the second day to confirm and evaluate the participants. The HICS intervention for nurses was a one-day workshop on disaster preparedness, which included the presentation of the concepts and principles of health management in disasters and the effects of disasters on health; a group work on assessing the risks and vulnerability of Imam Ali Hospital; providing materials related to planning and disaster preparedness with emphasis on the role of nurses; a team work on disaster management; and a round-table maneuvering and having a discussion session.

Data analysis was conducted with SPSS software version 13. To analyze the data collected from the HDMC, the mean of 19 components of the HICS was examined before and after the implementation of the system, and for analyzing the data collected from nurses, first the normality of their distribution was tested. Then, the paired samples t-test was used if data distribution was normal, and the Wilcoxon signed-rank test if data were not normally distributed.

Ethical considerations included obtaining an introductory letter from the university to hospital officials, obtaining consents from the participants and explaining the objectives of the study, confidentiality of the data, the right to withdraw from the study, and the right to benefit from results for hospital officials.

\section{Results}

According to the obtained results, $86.7 \%$ of the study participants had bachelor's degree; $50 \%$ of them had a work experience of 6-10 years; $80 \%$ had a history of managerial positions; $86.7 \%$ had an experience of disaster relief; and $66.7 \%$ had training experience in triage and primary care.

Assessment results obtained from the HDMC showed that the pre-test mean score of disaster preparedness was 87.333, which increased to 130.812 after intervention. This indicated that the disaster preparedness increased from "high" to "very high" level, although this increase was low in terms of disaster management planning, training, coordination, communication with the media, staff, follow-up, and post-disaster activities (Table 1).

Assessment results obtained from nurses reported that their mean scores of disaster preparedness increased from 44.63 to 51.33 after intervention in terms of knowledge, and from 12.93 to 76.26 in terms of practice. Their mean of total score also increased from 132.63 (moderate level) to 207.56 (high level) after intervention. In the three scales of knowledge, practice, and attitude, the $\mathrm{P}=0.000$; hence, the assumption of the equality of means was rejected (Table 2).

To compare the disaster preparedness level of nurses before and after HICS intervention, the KolmogorovSmirnov test was performed. Its results showed that P-value of post-test attitude $(0.000)$, pre-test practice $(0.000)$, post-test practice $(0.011)$, and post-test preparedness $(0.003)$ was less than 0.05 ; hence, the assumption of normality was rejected; however, for pre-test knowledge (0.881), post-test knowledge $(0.176)$, and pre-test attitude (0.150), the $\mathrm{P}>0.05$ and thus for these data, assumption of the normality cannot be rejected.

The pre-test and post-test mean scores of disaster preparedness knowledge (Table 3) showed that nurses' score increased from 44.633 before intervention to 51.333 after intervention. Since $\mathrm{P}=0.000$, the assumption of the equality of means was rejected in terms of disaster preparedness knowledge. Regarding the nurses' attitude towards disaster preparedness, results reported an increase from 75.067 before intervention to 79.033 after intervention (Table 4 ). Since $\mathrm{P}=0.000$, the assumption of the equality of means was also rejected in terms of attitude towards disaster preparedness.

In terms of disaster preparedness practice, results showed an increase from 12.933 before intervention to 76.267 after intervention (Table 5). Since $\mathrm{P}=0.000$, the assumption of the equality of means was also rejected in terms of disaster preparedness practice. Overall, mean score of disaster preparedness in nurses increased from 130.630 before intervention to 207.570 after intervention (Table 6), and the assumption of the equality of means was also rejected in terms of disaster preparedness $(\mathrm{P}=0.000)$.

\section{Discussion}

The results of the current study revealed that Imam Ali Hospital prepared the basic principles of disaster management before the study onset, i.e. setting responsibilities and assigning them to individuals, and 
Table 1. The pre-test and post-test mean scores of HICS components obtained from participants

\begin{tabular}{|c|c|c|c|}
\hline \multirow{2}{*}{ HICS Components } & \multicolumn{2}{|c|}{ Mean $\pm S D$} & \multirow{2}{*}{ Maximum Score* } \\
\hline & Pre-Test & Post-Test & \\
\hline Disaster management structure & $18.66 \pm 2.00$ & $22 \pm 0$ & 22 \\
\hline Disaster management plan & $10.11 \pm 3.62$ & $18.56 \pm 0.52$ & 20 \\
\hline Partner organizations & $2.88 \pm 1.96$ & $4.44 \pm 0.52$ & 5 \\
\hline Security plan & $4.55 \pm 1.94$ & $8.77 \pm 0.44$ & 10 \\
\hline Procurement & $10.44 \pm 3.71$ & $15 \pm 0$ & 18 \\
\hline Discharge \& transfer & $4.77 \pm 1.78$ & $6 \pm 0$ & 9 \\
\hline Fire extinguishing & $3.55 \pm 1.23$ & $6 \pm 0$ & 6 \\
\hline Structural safety & $3 \pm 0.50$ & $6 \pm 0$ & 6 \\
\hline Structural information & $3.77 \pm 0.44$ & $4 \pm 0$ & 4 \\
\hline Training & $3.88 \pm 1.05$ & $7 \pm 0$ & 8 \\
\hline Disinfection & $4.33 \pm 0.70$ & $5 \pm 0$ & 6 \\
\hline Coordination & $0.44 \pm 0.52$ & $3 \pm 0$ & 3 \\
\hline Communication with the media & $0 \pm 0$ & $4.22 \pm 0.44$ & 6 \\
\hline Staff & $3.33 \pm 2.06$ & $7 \pm 0$ & 7 \\
\hline Follow-up & $1.77 \pm 0.97$ & $4 \pm 0$ & 4 \\
\hline Cost reporting & $1.33 \pm 0.86$ & $2 \pm 0$ & 2 \\
\hline Documentation & $3 \pm 1.00$ & $4 \pm 0$ & 4 \\
\hline Back to normal state & $0.66 \pm 1.00$ & $2 \pm 0$ & 2 \\
\hline Post-disaster activities & $0.88 \pm 0.78$ & $3 \pm 0$ & 3 \\
\hline Total & $87.33 \pm 10.71$ & $130.81 \pm 1.36$ & 145 \\
\hline
\end{tabular}

Table 2. The pre-test and post-test mean scores of disaster preparedness obtained from nurses

\begin{tabular}{|c|c|c|}
\hline \multirow{2}{*}{ Disaster Preparedness Scale } & \multicolumn{2}{|c|}{ Mean } \\
\hline & Pre-Test & Post-Test \\
\hline Knowledge & 44.63 & 51.33 \\
\hline Attitude & 75.03 & 79.03 \\
\hline Practice & 12.93 & 76.26 \\
\hline Total & 132.63 & 207.56 \\
\hline
\end{tabular}


Table 3. Mean scores of disaster preparedness knowledge before and after HICS intervention

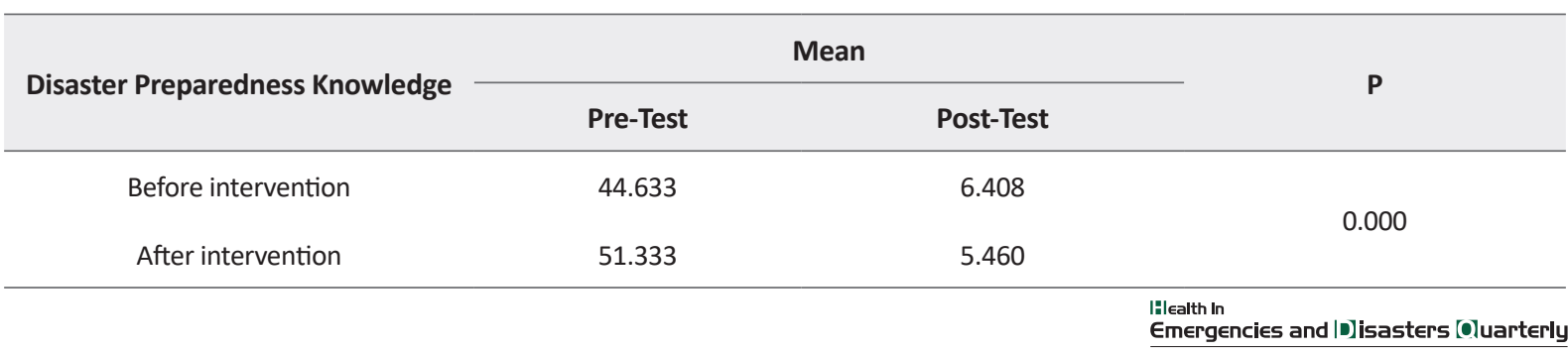

Table 4. Mean scores of attitude towards disaster preparedness before and after HICS intervention

\begin{tabular}{|c|c|c|c|}
\hline \multirow{2}{*}{ Attitude Towards Disaster Preparedness } & \multicolumn{2}{|c|}{ Mean } & \multirow{2}{*}{$\mathbf{P}$} \\
\hline & Pre-Test & Post-Test & \\
\hline \multirow[t]{2}{*}{ Before intervention } & 75.067 & 5.349 & \\
\hline & & & 0.000 \\
\hline After intervention & 79.033 & 1.752 & \\
\hline
\end{tabular}

Table 5. Mean scores of disaster preparedness practice before and after HICS intervention

\begin{tabular}{cccc}
\hline & & Mean & \\
Disaster Preparedness Practice & Pre-Test & Post-Test & P \\
\cline { 2 - 3 } Before intervention & 12.933 & 14.042 & 0.000 \\
After intervention & 76.267 & 24.901 & IPlealth in \\
Emergencies and |D]isasters [Oluarterly
\end{tabular}

prior to the intervention provided a platform to establish HICS. The mean total score of disaster preparedness before intervention was 87.33 out of 161 , which indicated that this hospital was highly prepared to deal with disasters. This hospital is located in an area exposed to natural disasters, including earthquakes and floods.

In 2003 Bam Earthquake, a large number of injured people were sent to this health care center for treatment and surgery, and the staff and officials of the hospital experienced emergency situations at a limited time. Next year, there was a powerful earthquake in Zarand County that killed about 1000 people and left hundreds of wounded and homeless people, where the hospital was faced with a high number of injuries.

The current study aimed at improving the disaster preparedness of the Crisis Committee in this hospital, and the pre-test scores of this committee indicated that the hospital was highly prepared. It should be noted that approximately one-third of the total score was related to the disaster management structure and planning and procurement, while in important areas such as training, patient follow-up, coordination, and communication with the media, the score was low.

Table 6. Mean scores of disaster preparedness before and after HICS intervention

\begin{tabular}{|c|c|c|c|}
\hline \multirow{2}{*}{ Disaster Preparedness Practice } & \multicolumn{2}{|c|}{ Mean } & \multirow{2}{*}{$\mathbf{P}$} \\
\hline & Pre-Test & Post-Test & \\
\hline Before intervention & 132.630 & 18.978 & \\
\hline & & & 0.000 \\
\hline After intervention & 207.570 & 30.549 & \\
\hline
\end{tabular}


Results of the current study were consistent with the findings of Higgins et al. (2004) using a checklist to evaluate the preparedness of 116 hospitals in Kentucky for mass casualty events. They showed disaster preparedness of hospitals, although the efforts were still in an early stage of development, and some critical capabilities such as isolation, decontamination, and syndromic surveillance were clearly underdeveloped [8].

Manley et al. (2006) in a study on realities of disaster preparedness of 1975 rural hospitals in the US showed that they were very prepared in dealing with cardiac emergencies and motor vehicle crash trauma, but were much less prepared for treating victims of chemical weapon attacks and bombings [11]. Another finding of the current study was the significant increase in knowledge, attitude, and practice of nurses in terms of disaster preparedness after HICS intervention $(\mathrm{P}=0.001)$ compared with their pre-test scores. In this regard, it was observed that disaster preparedness of nurses significantly increased after intervention $(\mathrm{O}=0.001)$. Improvement of nurses' disaster preparedness after implementation of disaster management educational program was consistent with other studies conducted in this area. Ireland et al. (2006) showed that by integrating the disaster preparedness principles into the community health nursing course and preparing maneuvers, the level of knowledge, attitude, and practice of nurses increased [12].

Ghanbari et al. (2011) used educational programs and round-table maneuvering as the intervention of nurses to deal with disasters and showed that the mean of scores in all dimensions of disaster preparedness (knowledge, attitude, and practice) were significantly different before and after intervention and during follow-up $(\mathrm{P}<0.001)$, where it increased significantly from 75.14 in pre-test to 104.77 in post-test $(\mathrm{P}<0.001)$ [13]. The current study had some limitations; the absence of control group for comparison, and high intensity of training courses due to the limitations of the hospital for holding workshops were some of the study limitations.

\section{Conclusion}

Establishment of a HICS and training of nursing staff can enhance the general readiness of the hospital, while improving the knowledge, attitude, and practice of nurses and the preparedness of Disaster Management Committee. Therefore, the continuation of the nursing training and deployment of HICS can significantly increase readiness in similar situations. According to the findings of the current study, a similar study with a longer follow-up period is suggested.

\section{Ethical Considerations}

\section{Compliance with ethical guidelines}

Ethical considerations included obtaining an introductory letter from the university to hospital officials, obtaining consents from the participants and explaining the objectives of the study, confidentiality of the data, the right to withdraw from the study, and the right to benefit from results for hospital officials.

\section{Funding}

The present paper was extracted from the MSc. thesis of the first author in Research Center in Emergency \& Disaster Health, University of Social Welfare and Rehabilitation Sciences.

\section{Authors contributions}

All authors contributed in preparing this article.

\section{Conflict of interest}

The authors declared no conflict of interest.

\section{Acknowledgements}

Authors would like to thank authorities of the University of Social Welfare and Rehabilitation Sciences, Treatment Deputy of Social Security Organization of Kerman Province, and officials and personnel of Imam Ali Hospital in Zarand for their valuable cooperation.

\section{References}

[1] Paul JA, Batta R. Models for hospital location and capacity allocation for an area prone to natural disasters. International Journal of Operational Research. 2008; 3(5):473-96. [DOI:10.1504/IJOR.2008.019170]

[2] Yousefi S, Khankeh H, Akbari Y, Dalvandi A, Bakhshi E. The effect of the implementation of the national program for hospital preparedness on the readiness of nurses under simulated conditions of incidents and disasters. Health in Emergencies \& Disasters Quarterly. 2016; 2(1):39-44. [DOI:10.18869/nrip.hdq.2.1.39]

[3] Khankeh HR, Mohammadi R, Ahmadi F. [Health care services at time of natural disasters: A qualitative study (Persian)]. Iran Journal of Nursing. 2007; 20(51):85-96 
[4] Djalali A, Castren M, Khankeh H, Gryth D, Radestad M, Öhlen $\mathrm{G}$, et al. Hospital disaster preparedness as measured by functional capacity: a comparison between Iran and Sweden. Prehospital and Disaster Medicine. 2013; 28(5):45461. [DOI:10.1504/IJOR.2008.019170]

[5] Bartley BH, Stella JB, Walsh LD. What a disaster? Assessing utility of simulated disaster exercise and educational process for improving hospital preparedness. Prehospital and Disaster Medicine. 2006; 21(4):249-55. [DOI:10.1017/ S1049023X00003782]

[6] Zaboli R, Tofighi Sh, Amerion A, Moghaddasi H. [Survey of Tehran city hospitals disaster preparedness for disaster (Persian)]. Journal of Military Medicine. 2006; 8(2):103-11.

[7] Djalali A, Castren M, Hosseinijenab V, Khatib M, Ohlen G, Kurland L. Hospital Incident Command System (HICS) performance in Iran; decision making during disasters. Scandinavian Journal of Trauma, Resuscitation and Emergency Medicine. 2012; 20(1):14. [DOI:10.1186/1757-7241-20-14]

[8] Higgins W, Wainright C, Lu N, Carrico R. Assessing hospital preparedness using an instrument based on the Mass Casualty Disaster Plan Checklist: Results of a statewide survey. American Journal of Infection Control. 2004; 32(6):327-32 [DOI:10.1016/j.ajic.2004.03.006] [PMID]

[9] Bigley GA, Roberts KH. The incident command system High-reliability organizing for complex and volatile task environments. Academy of Management Journal. 2001; 44(6):1281-99. [DOI:10.2307/3069401]

[10] Buck DA, Trainor JE, Aguirre BE. A critical evaluation of the incident command system and NIMS. Journal of Homeland Security and Emergency Management. 2006; 3(3):154752. [DOI:10.2202/1547-7355.1252]

[11] Manley WG, Furbee PM, Coben JH, Smyth SK, Summers $\mathrm{DE}$, Althouse RC, et al. Realities of disaster preparedness in rural hospitals. Disaster Management \& Response. 2006; 4(3):80-7. [DOI:10.1016/j.dmr.2006.05.001] [PMID]

[12] Ireland M, Ea E, Kontzamanis E, Michel C. Integrating disaster preparedness into a community health nursing course: One school's experience. Disaster Management \& Response. 2006; 4(3):72-6. [DOI:10.1016/j.dmr.2006.03.001]

[13] Ghanbari V, Maddah S, Khankeh H, Karimloo M. [The effect of a disaster nursing education program on nurses' preparedness for responding to probable natural disasters (Persian)]. Iran Journal of Nursing. 2011; 24(73):72-80. 
This Page Intentionally Left Blank 